\title{
Screening preoperative anxiety - when does it relate to the quality of life among patients before total joint replacement? Preliminary reports
}

\begin{abstract}
BACKGROUND
Anxiety among patients undergoing joint replacement increases the risk of post-surgery complications and mental health problems, and impairs health-related quality of life (HRQoL). Since clinical procedures require adequate, but possibly simple and cost-saving tools, an augmenting application of a one-item visual analogue scale for anxiety (VAS-A) has been observed. The purpose of the present study is to validate the VAS-A using the State-Trait Anxiety Inventory (STAI) and consider both as HRQoL predictors among patients waiting for total joint replacement.
\end{abstract}

\section{PARTICIPANTS AND PROCEDURE}

Patients ( $n=68,34 \%$ male), hospitalized for total hip or knee replacement, participated before surgery in this cross-sectional study. They completed the Nottingham Health Profile (NHP) to assess their HRQoL, the VAS-A and STAI for anxiety, and the Visual Analogue Scale for pain as a control variable.
RESULTS

Although the VAS-A correlated with the STAI score $(r=.29$, $p=.019$ for the state anxiety subscale), this convenient measure did not relate to the NHP results (NHP total score $\beta=-0.03, p=.799$ ), while the STAI results did, especially the trait subscale $(\beta=1.29, p<.001, \mathrm{Cl} 0.82$ to 1.75$)$.

\section{CONCLUSIONS}

The value of the VAS-A regarding HRQoL is limited while trait anxiety seems a disregarded factor significantly referring to HRQoL. Its assessment, in addition to the evaluation of temporary emotional states, might provide benefits in the clinical management of patients within surgery, orthopedic and rehabilitation care. Intervention possibilities for those with altered trait anxiety are discussed.

KEY WORDS

arthroplasty; well-being; visual analogue scale; STAI; pain

ORgANizATION - Department of Medical Psychology and Medical Communication, Second Faculty of Medicine, Medical University of Warsaw, Poland

authors' Contributions - A: Study design - B: Data collection - C: Statistical analysis - D: Data interpretation .

E: Manuscript preparation · F: Literature search · G: Funds collection

CORresponding AUthor - Marta Małgorzata Rzadkiewicz, Ph.D., Department of Medical Psychology and Medical Communication, Second Faculty of Medicine, Medical University of Warsaw, 14-16 Litewska Str., 00-575 Warsaw, Poland, e-mail: mrzadkiewicz@wum.edu.pl 


\section{BACKGROUND}

Total joint arthroplasty (TJA) is a surgical procedure where a dedicated prosthesis replaces the damaged parts of the joint, and is often offered to patients suffering from serious disability caused mostly by an advanced osteoarthritis, especially when the hip or knee is affected (Woolf \& Pfleger, 2003; Piscitelli et al., 2012). Patients who are qualified for total knee or hip arthroplasty (TKA/THA) experience multidimensional deterioration of health-related quality of life (HRQoL) before the surgery (Yildiz et al., 2010). The condition can additionally trigger/ intensify mental health problems, with anxiety being one of the leading ones (Ozcakir, Raif, Sivrioglu, \& Kucukcakir, 2011). Since the level of anxiety is usually elevated before surgery, it is recommended to be evaluated routinely (Aust et al., 2018). Anxiety relates negatively to HRQoL in various chronic diseases, with trait anxiety being particularly worth monitoring (Kepka et al., 2013). However, little is known about the relationship between anxiety and HRQoL in patients awaiting joint replacement (Ayers, Franklin, Trief, Ploutz-Snyder, \& Freund, 2004; Papakostidou et al., 2012). HRQoL fails to comprehensively explain post-surgery functional recovery status (Resnick et al., 2005). Both THA and TKA are often reported to improve physical functioning and HRQoL (Czyzewska, Glinkowski, \& Walesiak, 2014; Elmallah et al., 2016; Rat et al., 2010). At the same time, anxiety preceding TJA affects the postoperative functional status, satisfaction with joint replacement, general quality of health index, and increases the risk of complications, and pain, along with the experience of pain up to two years after surgery (Khatib, Jenkin, Naylor, \& Harris, 2016; Khatib, Madan, Naylor, \& Harris, 2015; Gill \& McBurney, 2013; Qi et al., 2016; Rasouli, Menendez, Sayadipour, Purtill, \& Parvizi, 2016; Singh \& Lewallen, 2013; Vissers et al., 2012). Ayers with coworkers (2004) observed that the preoperative mental component of the HRQoL measurement predicted the score of the physical component of the same tool six months after surgery, indicating the need for longterm emotional support to enhance patient recovery. Thus, there is partial scientific confirmation that long-term improvement of HRQoL after TJA might be disturbed by anxiety (Duivenvoorden et al., 2013; Khatib et al., 2015; Vissers et al., 2012). The way anxiety is understood and assessed might influence the mentioned associations.

Among patients waiting for TKA, the prevalence of mental disorders (self-reported as a comorbidity) reaches $18 \%$, with psychiatric or sedative medication use in $16.6 \%$ of this group (Khatib et al., 2016). Although after TJA the anxiety prevalence is reduced (Duivenvoorden et al., 2013; Singh \& Lewallen, 2013), it remains higher than in the general population
(Anxiety Disorder Association of America, 2016), which suggests a long-term issue. The psychological burden rebounds upon recovery and rehabilitation effectiveness, and anxiety appears to be one of the leading risk factors for deficient HRQoL after TJA. By addressing the patient's anxiety with appropriate relaxing, supportive or educational techniques the medical staff can raise the motivation and well being of their patients, boosting the whole process of recovery (Jokar, Yousefi, Yousefy, \& Sadeghi, 2017).

In non-psychiatric/psychological research, anxiety, specifically preoperative anxiety, is seldom defined (Wilson et al., 2016). To illustrate: there is a difference between a temporary state of anxiety when, e.g. hospitalization is seen as stressful, and trait anxiety describing a personal disposition to feel tension, even in neutral situations. The variety of tools for clinical measurement of anxiety might further cause the discrepancies between research findings (Julian, 2011; Khatib et al., 2015). Finally, whereas other mental health issues present similar, although weaker, patterns of relationships with treatment outcomes in TJA, only the measurement of anxiety tends to be shortened to comprise a one-item visual analogue scale (the VAS-A) (Facco et al., 2013).

The aim of this research was twofold: first, to explore preoperative anxiety in relation to HRQoL before TJA, and second to assess the validity of the VAS-A based on the State and Trait Anxiety Inventory (STAI) score. Based on the knowledge from the research mentioned earlier, this cross-sectional study was planned to verify the following hypotheses and research questions:

1. H0. A single item VAS-A scale is a valid scale to assess preoperative anxiety among patients awaiting TJA when confronted with the STAI-state but not the STAI-trait scale.

2. H0: Preoperatively assessed anxiety is related to HRQoL in TJA patients awaiting surgery.

If confirmed, the research questions listed below arise:

2a. How it is shaped - which HRQoL dimensions are related to anxiety?

$2 b$. Is the relationship between anxiety and HRQoL sensitive to the type of anxiety measurement?

2 c. Is the relationship between anxiety and HRQoL independent from the level of pain the patients experience?

Combining the most burdensome factors with a focus on multidimensional HRQoL measurement integrates the approaches from earlier studies and brings a new perspective on post-TJA improvement of HRQoL (Owczarek, 2010). Addressing the above problems can set the stage for a debate regarding pre-surgery anxiety screening and adjusted care procedures. 


\section{PARTICIPANTS AND PROCEDURE}

\section{PARTICIPANTS}

Patients $(N=68)$ hospitalized for TKA $(n=32,47.1 \%)$ or THA $(n=36,52.9 \%)$ due to osteoarthritis participated in the study (34\% male, $n=23)$ and were recruited in two settings: in the capital city of Warsaw $(n=34,50 \%)$ and the town of Ostrołęka (53,000 inhabitants, $n=34$, $50 \%$ ). Both hospital authorities approved carrying out the study in their wards. Consecutive patients admitted to the hospital to have TKA or THA were invited to participate. The exclusion criteria comprised any inability to independently fill in the questionnaires or information, based on medical records, about experiencing a current psychiatric/substance abuse problem. Participants in the study were 50-84 years old (age: $M=65.85, S D=10.33), 15 \%$ with higher education, $62 \%$ living with a spouse/partner, $56 \%$ receiving a pension, self-reported illness duration from 1 to 22 years (illness duration $M=6.10, S D=4.98$ ), had waited from 21 to 720 days for the surgery (waiting days $M=100.71$, $S D=116.05$, median $=90.00), 23 \%(n=16)$ for revision TJA. All were personally contacted one to three days prior to the planned surgery and, after being assured regarding the anonymous and confidential character of the data collection, all gave their written informed consent for participation.

\section{MEASUREMENTS}

Participants filled in the Polish adaptation of the Nottingham Health Profile (NHP) (Wrześniewski, 1997), to assess their HRQoL, a self-reported preoperative visual analogue scales for pain (VAS-P) and anxiety (VAS-A) and the State-Trait Anxiety Inventory (STAI) - Polish version (Wrześniewski, Sosnowski, \& Matusik, 2002). They also provided basic sociomedical data.

The STAI is recommended as the most appropriate measurement of preoperative anxiety (Wilson et al., 2016). Moreover, only this tool permits the distinction between temporary and dispositional anxiety. This assessment also has a normalized Polish adaptation. A STAI score greater than 40 is considered to indicate high/clinical anxiety in the adult population (Knight, Waal-Manning, \& Spears, 1983). In clinical research, a cut-off point for a preoperative breast cancer anxiety score greater than 44 was assumed as high (Millar, Jelicic, Bonke, \& Asbury, 1995). However, an even higher threshold of 55 points is advised for older adults (Kvaal, Ulstein, Nordhus, \& Engedal, 2005).

The VAS-A is considered to be an equivalent method, but far less time-consuming (x10) and simple (Facco et al., 2013; Julian, 2011; Wilson et al., 2016). Considering cost-effectiveness, and reducing patient burden, it is important to establish whether both methods have similar relationships with other factors reflecting patients' well-being. According to Facco et al. (2013), the VAS-A is confirmed as reliable by its moderate but significant correlations with the STAI-State subscale. Although there is no established cut-off point in preoperative anxiety assessed on the VAS-A, some studies advise a value of 5 or 6 (Millar et al., 1995). For the VAS-P scale, pain higher than the maximum acceptable level is usually considered as being 5 or more (Gill \& McBurney, 2013).

The NHP assesses generic HRQoL (Hunt, McKenna, McEwen, Williams, \& Papp, 1981a), and has been employed among osteoarthritis patients (Busija et al., 2011; Hunt, McKenna, \& Williams, 1981b) with good reliability, validity, and sensitivity to disease activity (Hussein, McKenna, \& Scott, 1997) and self-rated health status (Uutela, Hakala, \& Kautiainen, 2003). It comprises six sections - pain, energy, emotional reaction, sleeping, social isolation and physical mobility. Additionally, a general score can be calculated. The more problems a patient experiences, the higher is the score. This scale was chosen for having comparatively low probability of a ceiling effect, an optimal understanding of question formulation among elderly patients, and is advised as covering the areas particularly important in rheumatology (mobility, pain, sleep). However, the NHP also has its shortcomings, e.g. a common floor effect among healthier populations (Busija et al., 2011; Carr, 2003).

\section{STATISTICAL ANALYSIS}

The data were analyzed with IBM SPSS v. 24 software, except for the comparison of the two STAI subscales scores where Cohen's $d$ was applied to assess the size effect. Mean values $(M)$ and standard deviations $(S D)$ are quoted for illustrative purposes. Since the scores of some socio-demographic variables were not normally distributed, non-parametric statistical tests were executed. The main analyses were based on multiple linear regression modeling, with variables entered stepwise. The patients' age, gender and education level were included as control variables, pain at night and when walking as confounding variables, and VAS-A, STAI-State, and STAI-Trait scores as independent variables. The scores calculated for individual sections and total NHP were separately introduced as outcome variables.

\section{RESULTS}

\section{LEVEL OF ANXIETY AND HRQOL}

For anxiety measured on the VAS-A the results show the mean $M=4.79$ with standard deviation $S D=2.70$. Regarding the threshold for high anxiety, $64.7 \%$ of
Preoperative anxiety and quality of life 
Marta Małgorzata

Rzadkiewicz,

Stanisław

Wójtowicz,

Hanna Rozenek participants had a VAS-A score of $\geq 5$, and $20.6 \%$ had a VAS-A score of $\geq 6$.

Anxiety measured with the STAI revealed for the State $(M=51.27, S D=7.54)$ and the Trait $(M=43.81$, $S D=8.04$ ) subscale $89 / 92$ (for men/women) and 70/66 percentiles respectively (Wrześniewski et al., 2002). This group was thus characterized by an increased level of anxiety. The threshold score representing a high level of anxiety (40+ points) was exceeded by $92.2 \%$ of participants on the State and $60.3 \%$ on the Trait subscale. With age-adjusted standards $(55+$ points) significantly lower rates $-30.9 \%$ on the State and $5.9 \%$ on the Trait subscale - were observed. The comparison of the STAI-State and Trait scores showed a meaningful difference (Cohen's $d=.96$, effect size $r=.43$ ), indicating that state anxiety was higher in this group than trait anxiety.

The mean general NHP score was $M=47.61$ $(S D=18.90)$. The strongest HRQoL impairment concerned the sections of pain $(M=71.51, S D=22.94)$ and movement $(M=59.38, S D=22.89)$, followed by sleep disturbance $(M=51.47, S D=36.62)$ and deficits of energy $(M=51.96, S D=34.26)$. The scores were lower for emotional problems $(M=34.31, S D=25.30)$ or social withdrawal $(M=17.06, S D=25.22)$ whereas, for the additional list of everyday problems, they rose to $M=59.87, S D=25.08$.

\section{SOCIO-DEMOGRAPHIC DATA IN RELATION TO ANXIETY AND HRQOL}

The waiting time for hospital admission, illness duration, primary/revision replacement, affected joint, and level of pain when walking and at night were included in the analysis. Differences concerning anxiety were found between men and women, but only on the VAS-A scale $(M=3.26, S D=1.94, M=5.58$, $S D=2.71$ respectively), where women tended to score higher. Patients awaiting primary surgery did not differ from those before revision surgery on any measure of anxiety (all $p>0.4$ ). Other relationships between socio-demographic and medical data and anxiety level are presented in Tables 1 and 2 .

\section{ANXIETY MEASURES AND THE ASSESSMENT OF PAIN EXPERIENCE}

The three measures of anxiety, along with two measures of pain, were included in partial correlation while controlling for age, gender and education of participants (see Table 3). This analysis reveals a relationship of moderate strength between STAI-State and the VAS-A scale $(r=.29, p=.019)$ but not STAI-Trait, confirming the validity of the VAS-A. Thus, the first

Table 1

Socio-demographic data and anxiety scores

\begin{tabular}{lccc}
\hline & VAS-A & STAI-State & STAI-Trait \\
\hline Gender & $\boldsymbol{Z}=-\mathbf{3 . 4 7}$ & $Z=-1.32$ & $Z=-1.31$ \\
Mann-Whitney $U$ & $\boldsymbol{p}<\mathbf{. 0 0 1}$ & $p=.185$ & $p=.190$ \\
Age & $\rho=0.09$ & $\rho=\mathbf{0 . 3 2}$ & $\rho=-0.04$ \\
Spearman's $\rho$ & $p=.470$ & $\boldsymbol{p}=\mathbf{. 0 0 8}$ & $p=.777$ \\
Education & $\rho=-0.04$ & $\rho=-0.13$ & $\rho=-\mathbf{0 . 3 3}$ \\
Spearman's $\rho$ & $p=.737$ & $p=.303$ & $\boldsymbol{p}=\mathbf{. 0 0 7}$ \\
\hline
\end{tabular}

Note. VAS-A - visual analogue scale - anxiety, STAI - State and Trait Anxiety Inventory.

Table 2

Illness-related data and anxiety scores

\begin{tabular}{lccc}
\hline & VAS-A & STAI-State & STAI-Trait \\
\hline Waiting time & $\rho=-0.13$ & $\rho=-0.12$ & $\rho=-0.05$ \\
Spearman's $\rho$ & $p=.277$ & $p=.314$ & $p=.708$ \\
Illness duration & $\rho=0.10$ & $\rho=0.02$ & $\rho=0.10$ \\
Spearman's $\rho$ & $p=.404$ & $p=.900$ & $p=.414$ \\
Primary/revised surgery & $Z=-0.44$ & $Z=-0.31$ & $Z=-0.83$ \\
Mann-Whitney $U$ & $p=.663$ & $p=.756$ & $p=.409$ \\
Knee/hip & $Z=-0.71$ & $Z=-0.20$ & $Z=-1.51$ \\
Mann-Whitney $U$ & $p=.478$ & $p=.839$ & $p=.130$ \\
\hline
\end{tabular}

Note. VAS-A - visual analogue scale - anxiety, STAI - State and Trait Anxiety Inventory. 
hypothesis is confirmed, but only when the VAS-A is used as a measurement of momentary anxiety, and hence cannot be generalized.

Patients' average reported pain was higher than the maximum acceptable level, both at night $(M=5.91$, $S D=2.51)$ and especially when walking $(M=6.99$, $S D=1.88)$. An intriguing finding was the lack of a relationship between patients' pain experience and anxiety within all the applied measurements (Table 3).

\section{ANXIETY IN RELATION TO HRQOL}

The three socio-demographic factors related to anxiety were incorporated into the multiple linear regression analysis as control variables. Both scores of the
VAS-P scales were entered as confounding variables. The results of this calculation for all NHP sections, general and problems score are available in Table 4.

The second hypothesis of this study, concerning the existence of a preoperative relationship between anxiety and HRQoL in the examined group of patients, was confirmed, since, in most cases, NHP scores were related to the level of anxiety. However, this relationship was found only when the STAI was applied, thus answering question 2a by showing that the divergence of the obtained relationships depended on the tools used to assess anxiety. For informative purposes the above findings are presented in a diagram (Figure 1) reflecting the means of anxiety measurement on one standardized scale for three levels of NHP total score (low, average, high). However, since
Preoperative anxiety and quality of life

Table 3

Relationship between pain and anxiety measures

\begin{tabular}{lccc}
\hline & VAS-A & STAI-State & STAI-Trait \\
\hline VAS-P walking & $r=.19$ & $r=.15$ & $r=.02$ \\
Spearman's $\rho$ & $p=.131$ & $p=.234$ & $p=.869$ \\
VAS-P at night & $r=.17$ & $r=.01$ & $r=.17$ \\
Spearman's $\rho$ & $p=.165$ & $p=1.00$ & $p=.173$ \\
VAS-A & & $r=.29, p=.019$ & $r=.13, p=.313$ \\
STAI-State & $\boldsymbol{r}=\mathbf{. 2 9 ,} \boldsymbol{p}=\mathbf{. 0 1 9}$ & & $\boldsymbol{r}=. \mathbf{2 5}, \boldsymbol{p}=\mathbf{. 0 4 4}$ \\
\hline
\end{tabular}

Note. VAS-P - visual analogue scale - pain, VAS-A - visual analogue scale - anxiety, STAI - State and Trait Anxiety Inventory.

\section{Table 4}

Multiple linear regression modeling for NHP sections, total score, and problems, with STAI-State, STAI-Trait, VAS-Anxiety, VAS - pain when walking, VAS - pain at night, gender, age and education entering stepwise into the model

\begin{tabular}{|c|c|c|c|c|c|}
\hline NHP dimension & Predictors & Adjusted $R^{2}$ & $\beta$ & $p$ & $95 \% \mathrm{Cl}$ \\
\hline Energy & STAI-Trait & .11 & 1.47 & .004 & -56.07 to 31.55 \\
\hline Pain & $\begin{array}{l}\text { pain at night } \\
\text { age }\end{array}$ & .27 & $\begin{array}{r}4.39 \\
-0.49\end{array}$ & $\begin{array}{r}<.001 \\
.039\end{array}$ & $\begin{array}{c}2.48 \text { to } 6.30 \\
-0.95 \text { to }-0.03\end{array}$ \\
\hline Emotional & $\begin{array}{l}\text { STAI-Trait } \\
\text { STAI-State }\end{array}$ & .29 & $\begin{array}{l}0.44 \\
0.25\end{array}$ & $\begin{array}{r}<.001 \\
.020\end{array}$ & $\begin{array}{l}0.73 \text { to } 2.06 \\
0.14 \text { to } 1.56\end{array}$ \\
\hline Sleeping problems & $\begin{array}{l}\text { STAI- Trait } \\
\text { STAI-State } \\
\text { pain at night }\end{array}$ & .25 & $\begin{array}{l}1.27 \\
1.25 \\
3.54\end{array}$ & $\begin{array}{l}.018 \\
.022 \\
.033\end{array}$ & $\begin{array}{l}0.23 \text { to } 2.31 \\
0.19 \text { to } 2.31 \\
0.29 \text { to } 6.78\end{array}$ \\
\hline Social withdrawal & STAI-Trait & .24 & 1.58 & $<.001$ & 0.91 to 2.24 \\
\hline Movement & STAI-Trait & .09 & 0.92 & .007 & 0.26 to 1.58 \\
\hline NHP - total score & $\begin{array}{l}\text { STAI-Trait } \\
\text { pain walking }\end{array}$ & .37 & $\begin{array}{l}1.29 \\
2.11\end{array}$ & $\begin{array}{r}<.001 \\
.037\end{array}$ & $\begin{array}{l}0.82 \text { to } 1.75 \\
0.13 \text { to } 4.10\end{array}$ \\
\hline NHP - problems & $\begin{array}{l}\text { age } \\
\text { pain at night }\end{array}$ & .17 & $\begin{array}{r}-0.87 \\
2.40\end{array}$ & $\begin{array}{l}.002 \\
.035\end{array}$ & $\begin{array}{c}-1.41 \text { to }-0.33 \\
0.17 \text { to } 4.62\end{array}$ \\
\hline
\end{tabular}

Note. NHP - Nottingham Health Profile, VAS-P - visual analogue scale - pain, VAS-A - visual analogue scale - anxiety, STAI - State and Trait Anxiety Inventory, $\mathrm{CI}$ - confidence interval. 
Marta Małgorzata

Rzadkiewicz,

Stanisław

Wójtowicz,

Hanna Rozenek

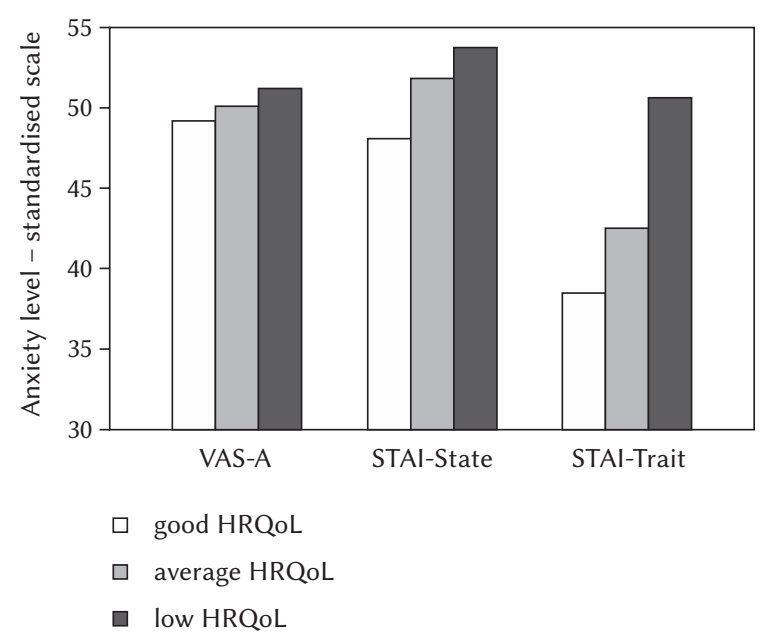

Figure 1. The level of anxiety ( 3 scales with standardized scores) among patients with good, average and low HRQoL (selection based on NHP scores frequencies). The figure does not depict regression analysis. VAS-A - Visual Analogue Scale - Anxiety, STAI - State and Trait Anxiety Index, HRQoL - health related quality of life.

a graphic display of the results with multiple regression analysis concerning three variables is unfeasible, this graph should be interpreted with caution.

The remaining analysis also shows that the VAS-A score was unrelated to the results of the NHP on any other dimension. Moreover, the relationship with NHP was not homogeneous, even within both STAI scales. While state anxiety referred to emotional and sleeping problems only (as a secondary factor), trait anxiety contributed to the variance of all but one (the pain) dimensions of the NHP on the first position, being also the main factor explaining the total score. This description simultaneously answered the question about the shape of the anxiety-HRQoL relationship (2b), revealing that anxiety - especially seen as a trait - explained most of the scores on the NHP. This relationship remains significant despite two types of patient's pain experience being included in the analysis, indicating an affirmative answer to the last question (2c) of this research.

\section{DISCUSSION}

The participants awaiting joint replacement surgery had elevated levels of preoperative anxiety and their HRQoL was seriously affected; a significant psychological burden was observed. Compared with other studies using NHP, in this sample HRQoL was lower or comparable to adults suffering from osteoarthritis (Hussein et al., 1997; Hayashi et al., 2016; Singh \& Lewallen, 2013) or those rating their health as low (Prieto, Alonso, Viladrich, \& Antó, 1996). Although the experience of pain determined here the scores in the NHP pain and sleeping problems sections, along with the total NHP score, it was found that the STAI-Trait score contributed even more to the understanding of preoperative HRQoL in patients waiting for TJA.

Despite the adjustment of the criteria for high anxiety, the rate of participants with elevated symptoms was still higher than the average prevalence in osteoarthritis reported elsewhere (Stubbs, Aluko, Myint, \& Smith, 2016) and in other clinical data, especially for state anxiety. The current study showed that the level of momentary state anxiety was higher than dispositional trait anxiety; nevertheless, the latter's relationship with all NHP sections was most evident. Thus, the relationship between anxiety and HRQoL is shaped differently, depending on whether state or trait anxiety is considered, answering the main research question of this study. It is important to note that, although the VAS-A correlated with the STAI-State anxiety measure, it did not relate to the NHP subscales as did the STAI-State. Finally, a hierarchy of adequate anxiety measurement regarding HRQoL among patients with TJA might be speculated here, with the VAS-A as an inadequate tool, STAI-State as relevant to HRQoL in terms of emotional burden, and STAI-Trait as the most appropriate with respect to all analyzed HRQoL dimension.

This research has confirmed the relationship between trait anxiety and HRQoL found earlier, preoperatively and postoperatively, among THA patients (Montin et al., 2007), despite a different measurement of quality of life and a less homogeneous sample being chosen. This observation sheds new light on anxiety as a determinant of HRQoL since, in most preoperative research, only a temporary emotional state is analyzed. Additionally, since two parallel measures were used to assess temporary anxiety, findings from this study indicate that a previously shown lack of relationship between state anxiety and HRQoL is unlikely to result only from the properties of the tools that have been used. One of the conjectures about how the trait anxiety rooted in personality might reflect on HRQoL among patients with osteoarthritis is through its longterm influence on pain perception, even to the extent of catastrophizing (Tang \& Gibson, 2005). However, the validity of this speculation seems doubtful considering the interesting lack of a relationship between anxiety and pain in the present study. What is important, especially in clinical practice, is that the VAS-A, as the least time-consuming and the easiest to apply measure of anxiety, failed to reveal a relationship with HRQoL.

There are some additional VAS-A limitations that might have contributed to the observed results. One of these is that the patient is expected to consciously recognize and acknowledge his or her anxiety (Wilson et al., 2016), whereas for other measures the way to obtain the score is less direct. This difference could partially explain the lack of VAS-A and NHP connec- 
tions. On this basis, the higher level of VAS-A among women in this study can also be interpreted to show that their fears, in contrast to men's fears, are socially more accepted, and thus easier to openly admit. The other VAS-A limitation relates to a wider range of subjectively rated responses resulting in central tendency bias (Hunt et al., 1981b). In the present study, this can be reflected by the considerable difference in the proportion of patients with a high level anxiety according to the VAS-A, depending on whether the cut-off point is located at the value of 5 or 6 . Both of the above limitations might also be responsible for the relatively weak correlation between the VAS-A and STAI scores. At the same time, the analyses executed here provide no support for the notion that the VAS-A used for preoperative measurement tends to overestimate anxiety in comparison with other tests, including the STAI (Facco et al., 2013).

Thus, a comprehensive diagnosis of anxiety seems particularly important when rating risk factors for medical or psychological complications in TJA, as well as estimating the current or future HRQoL of patients. Furthermore, because the intent of the STAI-Trait scale is to characterize a longstanding trait, clinicians and researchers should be mindful of this if seeking scales to detect anxiety or HRQoL changes over a relatively short period of time. In general, for these purposes, many have opted to solely use the STAI-State subscale for the detection of longitudinal changes (Julian, 2011).

The level of pain participants experienced at night explained only HRQoL on the dimension referring to pain, which was a single one with no relation to anxiety. Pain at night also explained sleeping problems but as a third factor after the score on both subscales of the STAI, whereas pain when walking contributed only to the total NHP score, again entering into the model after the STAI-Trait score. Thus, the answer to the last research question, concerning the role pain plays in the relationship between anxiety and HRQoL, states that the observed relationship remains eminently independent from the pain. Although pain naturally contributes to HRQoL, this research shows that the role of trait anxiety might overcome this relationship on many dimensions.

The main limitation of the current study is that it presents cross-sectional data only, and a determination of causality or prospective changes is unjustified. Knowing these shortcomings, a speculation that osteoarthritis, by influencing HRQoL, might intensify long-term trait anxiety could not be excluded. Although Ho et al. (2011) presented a multivariate regression analysis where HRQoL was not found to be a predictor of anxiety among patients with rheumatoid arthritis, a prospective study on a larger sample should be conducted to analyze the causality of this reported relationship. Montin et al. (2007) describe a prospective relationship between trait anxiety and HRQoL, although weaker post- than preoperatively, and among THA patients only. Thus, the present findings complement earlier work but, nevertheless, need further support. Precise information about participants in terms of general health (comorbidities, previous surgery), having revision arthroplasty or being at working age are the other issues which should be analyzed in more detail in future research.

Since establishing the level and the associations of anxiety with HRQoL alone is insufficient to benefit patients, development of specialized pathways of integrated care is warranted. The research should comprise the examination of means theoretically related to anxiety alleviation, but simultaneously proven to work towards HRQoL in chronic illnesses. For example, optimism is seen as reducing pain perception and post-surgery anxiety (Pinto, McIntyre, Ferrero, Almeida, \& Araújo-Soares, 2013) with an additional optimism-anxiety association explaining the HRQoL level (Kepka et al., 2013); perceived self-efficacy refers to confidence, better self-management and treatment outcomes of the given health condition (Marks, 2009; Wylde, Dixon, \& Blom, 2012), whereas improvement in strategies of coping with stress (including disease-derived) have the potential to change the perception of the illness' impact (Garnefski et al., 2013). Probably the most efficient means, tested also among other populations, are rooted in cognitivebehavioral therapy (Chew, Griva, \& Cheung, 2016) or actions combining physical rehabilitation (Chou \& Chen, 2019; Kim et al., 2012), with education allowing adequate TJA-related expectations (Neuprez et al., 2016; Şendir, Büyükyılmaz, \& Muşovi, 2013).

\section{CONCLUSIONS}

Anxiety assessed prior to surgery was found to be related to most of the HRQoL dimensions; hence a detailed preoperative measurement of anxiety should be of help when addressing HRQoL problems among patients expecting TKA/THA. Although useful in terms of cost and burden reduction in other assessments, the one-item VAS-A is not advised as an eligible tool for the above purposes since it measures momentary anxiety and is not associated with any HRQoL dimension. At the same time, dispositional, long-term trait anxiety, assessed with the STAI-Trait subscale, appears as a meaningful factor and, as such, should be screened for at least as often as state anxiety. Therefore the appropriate tools for anxiety assessment should be carefully selected as they might have different relationships to quality of life, especially if prospective analyses are to be conducted.

Trait anxiety should be considered as a potential confounder of HRQoL changes after surgery, rehabilitation or other dedicated interventions, and needs to be addressed to obtain the most from medical intervention in terms of outcomes and improvement of
Preoperative anxiety and quality of life 
patient HRQoL. Sensitive treatment and education could benefit from incorporation of actions aimed at long-term anxiety reduction to promote good HRQoL. Pre-surgery screening for anxiety is worth further study as this might help predict the need for pre- and postoperative therapeutic actions, and an assessment of their effectiveness, including improvements in patients' quality of life.

Marta Małgorzata Rzadkiewicz, Stanisław Wójtowicz, Hanna Rozenek

\section{References}

Anxiety Disorder Association of America (2016). Prevalence of anxiety in general population by Anxiety Disorder Association of America. Retrieved from http://www.adaa.org/about-adaa/press-room/ facts-statistics

Aust, H., Eberhart, L., Sturm, T., Schuster, M., Nestoriuc, Y., Brehm, F., \& Rüsch, D. (2018). A crosssectional study on preoperative anxiety in adults. Journal of Psychosomatic Research, 111, 133-139. https://doi.org/10.1016/j.jpsychores.2018.05.012

Ayers, D. C., Franklin, P. D., Trief, P. M., Ploutz-Snyder, R., \& Freund, D. (2004). Psychological attributes of preoperative total joint replacement patients: implications for optimal physical outcome. Journal of Arthroplasty, 19, 125-130.

Busija, L., Pausenberger, E., Haines, T. P., Haymes, S., Buchbinder, R., \& Osborne, R. H. (2011). Adult measures of general health and health-related quality of life: Medical Outcomes Study Short Form 36-Item (SF-36) and Short Form 12-Item (SF-12) Health Surveys, Nottingham Health Profile (NHP), Sickness Impact Profile (SIP), Medical Outcomes Study Short Form 6D (SF-6D), Health Utilities Index Mark 3 (HUI3), Quality of WellBeing Scale (QWB), and Assessment of Quality of Life (AQoL). Arthritis Care and Research, 63, 383-412.

Carr, A. (2003). Adult measures of quality of life: The Arthritis Impact Measurement Scales (AIMS/ AIMS2), Disease Repercussion Profile (DRP), EuroQoL, Nottingham Health Profile (NHP), Patient Generated Index (PGI), Quality of Well-Being Scale (QWB), RAQoL, Short Form-36 (SF-36), Sickness Impact Profile (SIP), SIP-RA, and World Health Organization's Quality of Life Instruments (WHOQoL, WHOQoL-100,WHOQoL-Bref). Arthritis Care \& Research, 49, S113-S133. https://doi.org/ 10.1002/art.11414

Chew, E., Griva, K., \& Cheung, P. P. (2016). Evaluation of coping strategies in established rheumatoid arthritis patients: emergence of concealment in an Asian cohort. International Journal of Rheumatic Diseases, 19, 1069-1077.

Chou, L. N., \& Chen, M. L. (2019). Effects of elastic band exercise on lower limb rehabilitation of elderly patients undergoing total knee arthroplas- ty. Rehabilitation Nursing, 44, 60-66. https://doi. org/10.1097/rnj.0000000000000109

Czyżewska, A., Glinkowski, W. M., \& Walesiak, K. (2014). Effects of preoperative physiotherapy in hip osteoarthritis patients awaiting total hip replacement. Archives of Medical Science, 10, 985-991.

Duivenvoorden, T., Vissers, M. M., Verhaar, J. A., Busschbach, J. J., Gosens, T., Bloem, R. M., BiermaZeinstra, S. M., \& Reijman, M. (2013). Anxiety and depressive symptoms before and after total hip and knee arthroplasty: a prospective multicentre study. Osteoarthritis and Cartilage, 21, 1834-1840.

Elmallah, R. K., Chughtai, M., Adib, F., Bozic, K. J., Kurtz, S. M., \& Mont, M. A. (2016). Determining Health-Related Quality-of-Life Outcomes Using the SF-6D Following Total Hip Arthroplasty. Journal of Bone and Joint Surgery, 99, 494-498.

Facco, E., Stellini, E., Bacci, C., Manani, G., Pavan, C., Cavallin, F., \& Zanette, G. (2013). Validation of visual analogue scale for anxiety (VAS-A) in preanesthesia evaluation. Minerva Anestesiologica, 79, 1389-1395.

Garnefski, N., Kraaij, V., Benoist, M., Bout, Z., Karels, E., \& Smit, A. (2013). Effect of a cognitive behavioral self-help intervention on depression, anxiety, and coping self-efficacy in people with rheumatic disease. Arthritis Care and Research, 65, 1077-1084.

Gill, S. D., \& McBurney, H. (2013). Does exercise reduce pain and improve physical function before hip or knee replacement surgery? A systematic review and meta-analysis of randomized controlled trials. Archives of Physical Medicine and Rehabilitation, 94, 164-176.

Hayashi, K., Kako, M., Suzuki, K., Hattori, K., Fukuyasu, S., Sato, K., Kadono, I., Sakai, T., Hasegawa, Y., \& Nishida, Y. (2016). Gait speeds associated with anxiety responses to pain in osteoarthritis patients. Pain Medicine, 17, 606-613.

Ho, R. C. M., Fu, E. H. Y, Chua, A. N. C., Cheak, A. A., \& Mak, A. (2011). Clinical and psychosocial factors associated with depression and anxiety in Singaporean patients with rheumatoid arthritis. International Journal of Rheumatic Diseases, 14, 37-47.

Hunt, S. M., McKenna, S. P., McEwen, J., Williams, J., \& Papp, E. (1981a). The Nottingham Health Profile: Subjective health status and medical consultations. Social Science and Medicine, 15, 221-229.

Hunt, S. M., McKenna, S. P., \& Williams, J. (1981b). Reliability of a population survey tool for measuring perceived health problems: a study of patients with osteoarthritis. Journal of Epidemiology and Community Health, 35, 297-300.

Hussein, D. A., McKenna, S. P., \& Scott, D. L. (1997). The Nottingham Health Profile as a measure of disease activity and outcome in rheumatoid arthritis. British Journal of Rheumatology, 36, 69-73. Jokar, F., Yousefi, H., Yousefy, A., \& Sadeghi, M. (2017). Begin again and continue with life: $A$ aualitative 
study on the experiences of cardiac rehabilitation patients. Journal of Nursing Research, 25, 344-352.

Julian, J. (2011). Measures of anxiety: State-Trait Anxiety Inventory (STAI), Beck Anxiety Inventory (BAI), and Hospital Anxiety and Depression ScaleAnxiety (HADS-A). Arthritis Care and Research, 63, S467-S472.

Kepka, S., Baumann, C., Anota, A., Buron, G., Spitz, E., Auquier, P., Guillemin, F., \& Mercier M. (2013). The relationship between traits optimism and anxiety and health-related quality of life in patients hospitalized for chronic diseases: data from the SATISQOL study. Health and Quality of Life Outcomes, 11, 134.

Khatib, Y., Jenkin, D., Naylor, J. M., \& Harris, I. A. (2016). Psychological traits in patients waiting for total knee arthroplasty. A cross-sectional study. Journal of Arthroplasty, 31, 1661-1666.

Khatib, Y., Madan, A., Naylor, J. M., \& Harris, I. A. (2015). Do psychological factors predict poor outcome in patients undergoing TKA? A systematic review. Clinical Orthopaedics and Related Research, 473, 2630-2638.

Kim, Y. S., Park, Y. S., Allegrante, J. P., Marks, R., Ok, H., Ok Cho, K., \& Garber, C. E. (2012). Relationship between physical activity and general mental health. Preventive Medicine, 55, 458-463.

Knight, R. G., Waal-Manning, H. J., \& Spears, G. F. (1983). Some norms and reliability data for the State-Trait Anxiety Inventory and the Zung SelfRating Depression scale. British Journal of Clinical Psychology, 22, 245-249.

Kvaal, K., Ulstein, I., Nordhus, I. H., \& Engedal, K. (2005). The Spielberger State-Trait Anxiety Inventory (STAI): the state scale in detecting mental disorders in geriatric patients. International Journal of Geriatric Psychiatry, 20, 629-634.

Marks, R. (2009). Comorbid depression and anxiety impact hip osteoarthritis disability. Disability and Health Journal, 2, 27-35.

Millar, K., Jelicic, M., Bonke, B., \& Asbury, A. J. (1995). Assessment of preoperative anxiety: comparison of measures in patients awaiting surgery for breast cancer. British Journal of Anaesthesia, 74, 180-183.

Montin, L., Leino-Kilpi, H., Katajisto, J. Lepistö, J., Kettunen, J., \& Suominen T. (2007). Anxiety and health-related quality of life of patients undergoing total hip arthroplasty for osteoarthritis. Chronic Illness, 3, 219-227.

Neuprez, A., Delcour, J. P., Fatemi, F., Gillet, P., Crielaard, J. M., Bruyère, O., \& Reginster, J. Y. (2016). Patients' expectations impact their satisfaction following total hip or knee arthroplasty. PLoS One, 11, e0167911.

Owczarek, K. (2010). The concept of quality of life. Acta Neuropsychologica, 8, 207-213.

Ozcakir, S., Raif, S. L., Sivrioglu, K., \& Kucukcakir, N. (2011). Relationship between radiological severity and clinical and psychological factors in knee osteoarthritis. Clinical Rheumatology, 30, 1521-1526.

Qi, A., Lin, C., Zhou, A., Du, J., Jia, X., Sun, L., Zhang, G., Zhang, L., \& Liu, M. (2016). Negative emotions affect postoperative scores for evaluating functional knee recovery and quality of life after total knee replacement. Brazilian Journal of Medical and Biological Research, 49, e4616.

Papakostidou, I., Dailiana, Z. H., Papapolychroniou, T., Liaropoulos, L., Zintzaras, E., Karachalios, T. S., \& Malizos, K. N. (2012). Factors affecting the quality of life after total knee arthroplasties: a prospective study. BMC Musculoskeletal Disorders, 13, 116.

Pinto, P. R., Mclntyre, T., Ferrero, R., Almeida, A., \& Araújo-Soares, V. (2013). Predictors of acute postsurgical pain and anxiety following primary total hip and knee arthroplasty. Journal of Pain, 14, 502-515.

Piscitelli, P., Iolascon, G., Di Tanna, G., Bizzi, E., Chitano, G., Argentiero, A., Neglia, C., Giolli, L., Distante, A., Gimigliano, R., Brandi, M. L., \& Migliore, A. (2012). Socioeconomic burden of total joint arthroplasty for symptomatic hip and knee osteoarthritis in the Italian population: a 5-year analysis based on hospitalization records. Arthritis Care and Research, 64, 1320-1327. https://doi.org/10.1002/acr.21706.

Prieto, L., Alonso, J., Viladrich, M. C., \& Antó, J. M. (1996). Scaling the Spanish version of the Nottingham Health Profile: evidence of limited value of item weights. Journal of Clinical Epidemiology, 49, 31-38.

Rasouli, M., Menendez, M. E., Sayadipour, A., Purtill, J. J., \& Parvizi, J. (2016). Direct cost and complications associated with total joint arthroplasty in patients with preoperative anxiety and depression. Journal of Arthroplasty, 31, 533-536.

Rat, A. C., Guillemin, F., Osnowycz, G., Delagoutte, J. P., Cuny, C., Mainard, D., \& Baumann, C. (2010). Total hip or knee replacement for osteoarthritis: mid- and long-term quality of life. Arthritis Care and Research 62, 54-62.

Resnick, B., Orwig, D., Wehren, L., Hawkes, W., Hebel, R., Zimmerman, S., \& Magaziner, J. (2005). Health-related quality of life: is it a good indicator of function post THR? Rehabilitation Nursing, 30, 46-54.

Şendir, M., Büyükyılmaz, F., \& Muşovi, D. (2013). Patients' discharge information needs after total hip and knee arthroplasty: a quasi-qualitative pilot study. Rehabilitation Nursing, 38, 264-271.

Singh, J. A., \& Lewallen, D. G. (2013). Medical and psychological comorbidity predicts poor pain outcomes after total knee arthroplasty. Rheumatology, 52, 916-923.

Stubbs, B., Aluko, Y., Myint, P. K., \& Smith, T. O. (2016). Prevalence of depressive symptoms and anxiety in osteoarthritis: a systematic review and meta-analysis. Age and Ageing, 45, 228-235.
Preoperative anxiety and quality of life 
Marta Małgorzata

Rzadkiewicz,

Stanisław

Wójtowicz,

Hanna Rozenek
Tang, J., \& Gibson, S. J. (2005). A psychophysical evaluation of the relationship between trait anxiety, pain perception, and induced state anxiety. Journal of Pain, 6, 612-619.

Uutela, T., Hakala, M., \& Kautiainen, H. (2003). Validity of the Nottingham Health Profile in a Finnish out-patient population with rheumatoid arthritis. Rheumatology, 42, 841-845.

Vissers, M. M., Bussmann, J. B., Verhaar, J. A., Busschbach, J. J., Bierma-Zeinstra, S. M., \& Reijman, M. (2012). Psychological factors affecting the outcome of total hip and knee arthroplasty: a systematic review. Seminars in Arthritis and Rheumatism, 41, 576-588.

Wilson, C. J., Mitchelson, A. J., Tzeng, T. H., El-Othmani, M. M., Saleh, J., Vasdev, S., LaMontagne, H. J., \& Saleh, K. (2016). Caring for the surgically anxious patient: a review of the interventions and a guide to optimizing surgical outcomes. American Journal of Surgery, 212, 151-159.

Woolf, A. D., \& Pfleger, B. (2003). Burden of major musculoskeletal conditions. Bulletin of the World Health Organization, 81, 646-656.

Wrześniewski, K. (1997). Badanie subiektywnego stanu zdrowia za pomocą polskiej adaptacji the Nottingham Health Profile [Evaluating subjective health status with Polish adaptation of Nottingham Health Profile]. In J. B. Karski, H. Kirschner, \& J. Leowski (Eds.), Wspótczesne potrzeby i możliwości pomiaru zdrowia [Current needs and possibilities in health assessment] (pp. 37-41). Warsaw: Ignis.

Wrześniewski, K., Sosnowski, T., \& Matusik, D. (2002). Inwentarz Stanu i Cechy Lęku STAI - polska adaptacja STAI. Podręcznik [Polish adaptation of State and Trait Anxiety Index]. Warsaw: PTP.

Wylde, V., Dixon, S., \& Blom, A. W. (2012). The role of preoperative self-efficacy in predicting outcome after total knee replacement. Musculoskeletal Care, 10, 110-118.

Yildiz, N., Topuz, O., Gungen, G. O., Deniz, S., Alkan, H., \& Ardic, F. (2010). Health-related quality of life (Nottingham Health Profile) in knee osteoarthritis: correlation with clinical variables and selfreported disability. Rheumatology International, 30, 1595-1600. 